\title{
Non-destructive determination of taste- related compounds in tomato using NIR spectra
}

(i) The corrections made in this section will be reviewed and approved by journal production editor.

Ginés Ibáñeza ibanezg@uji.es, Jaime Cebolla-Cornejo ${ }^{b, 1}$ jaicecor@btc.upv.es, Raúl Martí ${ }^{\mathrm{b}}$ raumarre@upvnet.upv.es, Salvador Rosellóa,1,* rosello@uji.es, Mercedes Valcárcel ${ }^{b}$ mervalge@upvnet.upv.es

aUniversitat Jaume I, Unidad Mixta de Investigación Mejora de la Calidad Agroalimentaria UJI-UPV. Departament de Ciències Agràries i del Medi Natural, Avda. Sos Baynat s/n, 12071 Castellón, Spain

bUniversitat Politècnica de València. Unidad Mixta de Investigación Mejora de la Calidad Agroalimentaria UJI-UPV. COMAV. Cno. de Vera s/n, 46022 Valencia, Spain

*Corresponding author.

${ }^{1}$ These authors contributed equally to the work.

\section{Abstract}

Near infrared (NIR) diffuse reflectance was used to predict the contents of taste-related compounds of tomato. Models were obtained for several varietal types including processing tomato, cherry and cocktail tomato, mid-sized tomato and tomato landraces, with a wide range of varieties. Good performance was obtained for the prediction of soluble solids, sugars and acids, considering a non-destructive methodology applied to fruits with different internal structure. Specific models averaged RMSEP (\%mean) values lower than $6.1 \%$ for SSC, $13.3 \%$ for fructose, $14.1 \%$ for glucose, $12.7 \%$ for citric acid, $13.8 \%$ for malic acid and $21.9 \%$ for glutamic acid. The performance was dependent on varietal type. General models with a higher number of samples and variation did not improve the performance of specific models. The models obtained, either specific or general, couldn't be extrapolated to external assays 
and an internal calibration would be required for each assay in order to provide a reliable performance.

Keywords :Fructose; Glucose; Citric; Breeding; Solanum lycopersicum L.

\section{Introduction}

Consumers are often disappointed with the flavor of tomatoes (Solanum lycopersicum L.). Several causes explain this situation, ranging from poor genetic material to harvest and handling procedures (Baldwin et al., 2000). Tomato flavor is defined by taste and aroma. Taste is determined by the accumulation of sugars, mainly fructose and glucose, organic acids, mainly citric and malic acid, and the relationship among them. A prominent role for glutamic acid has also been suggested (Bucheli et al., 1999). Increased levels of sugars and acids raised flavor acceptability, though there are maximum levels of acids above which further increases negatively affect consumer acceptability (Malundo et al., 1995). On the other hand, tomato aroma is defined by the accumulation of volatiles. Unlike other crops, aroma in tomato is rather complex, determined by the accumulation and interaction of multiple volatile compounds with none of them holding a prominent role (Baldwin et al., 2000).

Both taste and aroma are also inter-related. Some volatiles associated with fruity or floral notes can enhance the perception of sweetness, and other related to green notes can enhance the perception of sourness (Baldwin et al., 1998). On the other hand, sugars also affect aroma perception. Increased sugar levels enhance the perception of overall, ripe tomato, sweet tomato and tropical aroma notes. Furthermore, increased levels of acids also affect aroma perception. In this case, raising the perception of overall, tropical, ripe tomato and green aroma notes. It also causes a shift from floral and sweet tomato aroma and sweet taste towards bitter and citrus tastes and earthy, green, viney and musty notes (Baldwin et al., 2008).

The development of high-quality tomato productions has become an important objective in order to supply market segments, where some customers value niche products characterized by organoleptic features, giving less importance to the visual quality of the product and willing to pay a premium price (Bazzani and Canavari, 2013). This added value is especially important in the current market context, as after the financial crisis, the level of volatility in tomato prices is especially high and although the prices of tomato for consumers seem to be quite stable, price fluctuations in the chain damage the rest of the agents (Sidhoum and Serra, 2016).

For this purpose, it is necessary to develop new high-quality varieties to offer improved genotypes, to evaluate the growing conditions that optimize the expression of these genotypes and finally to monitor the production to assure quality standards. Although 
the recovery of positive alleles involved in the accumulation of volatile compounds that were present in tomato landraces has been proposed (Tieman et al. (2017), the truth is that it is not feasible to analyse the aroma of high quantity of samples at an affordable cost. Accordingly, most emphasis has been placed in the evaluation the accumulation of the sugar and acids, which also play a crucial role in the improvement of tomato flavor. Traditionally, these taste-related compounds have been indirectly measured with gross determinations involving soluble solid contents (SSC) and titratable acidity. But it has been described that sucrose equivalents calculated from the individual accumulation of fructose and glucose is a far better predictor of sweetness and tomato acceptability ( Baldwin et al., 1998). And the same applies to organic acids, as it has been reported the positive influence of free acids on sourness (Tandon et al., 2003).

Near-infrared (NIR) spectroscopy offers several advantages over the precise determination of sugars and acids via direct analytical methods based on high pressure liquid chromatography or capillary electrophoresis. It entails an indirect analysis, as NIR data is related to the actual sugar and acid content using chemometrics. Different algorithms have been used for this purpose. In the case of fruit and vegetables the most widely used are least squares regression, LSR, multiple linear regression, MLR, partial least squares, PLS, and principal component regression, PCR (Naes et al., 2002). Among them, PLS is usually preferred over other alternatives for quantification purposes, and PCA as an explorative method (Bureau et al., 2019). In fact, most researches involving spectroscopic data and with NIR and FTIR data choose PLS models (Arendse et al., 2018; Bureau et al., 2019).

The most notable advantage of NIR indirect quantification is that it enables nondestructive indirect determinations, highly valuable in applications that require straightforward, speedy characterization of samples (Blanco and Villarroya, 2002). For this purpose, it has been used in quality analysis of fruits and vegetables. But most works related to taste are targeted to predict gross measurements such as soluble solids contents (SSC) or titratable acidity and using a limited number of varieties ( Arendse et al., 2018). Nevertheless, the lacking availability of scientific evidence of the accuracy of these systems is considered a major drawback (Porep et al., 2015).

In this context, several questions have driven the development of the present work. Can efficient NIR PLS regression models be obtained to predict not only SSC but also major sugars and acids in diverse heterogeneous materials with similar characteristics? And in that case, are particular calibrations needed for each assay or general models can be satisfactorily extrapolated?

\section{Material and methods}

\subsection{Plant material}


Five sets of samples, each one with a specific material, were used to develop prediction models. The sample sets were configured considering varietal types, usually determined by their size (e.g. cherry and cocktail tomato) and purpose (e.g. processing tomato). The first sample set included 180 samples belonging to eight processing tomato varieties grown with different water and fertilization regimes in Navarra (Spain). The 168 samples from the second sample set were similar but were obtained in Extremadura, a different environment with warmer and sunnier conditions. These samples were obtained during the development of different agronomical studies (Lahoz et al., 2016; Martí et al., 2018). In both cases the fruits had a width in the range of 40 $50 \mathrm{~mm}$. The third sample set included 106 samples of 32 varieties of cherry and cocktail tomato (width range $20-35 \mathrm{~mm}$ ) obtained from local markets. The fourth sample set was more heterogeneous. It represented 108 samples of mid-sized tomatoes (width range $40-82 \mathrm{~mm}$ ) from 25 varieties including ribbed flat, rounded, plum and cluster tomatoes from commercial and landrace varieties. It was also obtained from local markets. Finally, the fifth sample set included 88 samples of 11 accessions of Spanish tomato landraces (width range 60-120 $\mathrm{mm}$ ) of the "Moruno" type, ribbed flat tomatoes similar to the beef type, grown in Albacete (Spain) and kindly provided by Dr. Moreno.

Each specific sample set and a general set with the 650 tomato samples were used for the calculation of models predicting SSC, sugar and acid contents from NIR spectra. In all cases, fully ripe fruits were sampled.

\subsection{Acquisition of NIR spectra}

All the fruits were washed with water and dried with cellulose tissue. The measurements of the NIR spectrum were carried out at four different and equidistant points in the equatorial peripheral zone of each fruit, as following the four cardinal points, (Hahn, 2002), and measurements were averaged. The spectrum was obtained with a portable NIR spectrometer (Ocean Optics, Dunedin, FL, USA) with an InGaAs detector, covering the range between 902 and $2094 \mathrm{~nm}$, with measurements spaced $6.80 \mathrm{~nm}$, and an optic fibre probe that allowed measurements directly on fruits using diffuse reflectance. The same probe was used for all the varieties independently of the size of the fruit, and if had a space of $20 \mathrm{~mm}$ between the optical fibre and the edge of the probe. In order to calibrate the equipment a Teflon disk was used as reference, measuring the spectra several times per day.

\subsection{Quantification of sugars and acids with capillary electrophoresis}

Once the NIR spectra were acquired, the tomatoes were crushed and homogenized. The determination of the soluble solids content was carried out with the obtained tomato juice using a Pocket PAL- $\alpha$ digital refractometer (Atago, Tokyo, Japan). The remaining sample was stored at $-80^{\circ} \mathrm{C}$ until the other analytical determinations were made. 
The quantification of the reducing sugars fructose and glucose and the organic acids citric, malic and glutamic acids was performed by capillary zone electrophoresis (CZE) with an Agilent 7100 equipment (Agilent Technologies, Waldbronn, Germany) following the method described by Cebolla Cornejo et al., (2012).

\subsection{Chemicals and reagents}

Fructose, glucose, citric, malic and glutamic acids, hexadimethrine bromide (HDM), and 2,6-pyridine dicarboxylic acid (PDC), and sodium dodecyl sulfate (SDS) were purchased from Sigma-Aldrich (Steinheim, Germany). Ultrapure water was obtained using a Milli-Q water system (Millipore, Molsheim, France).

\subsection{Data analysis}

Each sample set was randomly divided into a calibration group (75\% of the samples), used to develop the calibration and cross-validation procedures of partial least squares (PLS) regressions, and a validation group (25\% of the samples), used to make predictions with the PLS developed. PLS method was selected considering that it is the preferred method for the quantification of sugars and acids in fruits and vegetables using spectroscopic data (Arendse et al., 2018; Bureau et al., 2019).

Before PLS regression, the NIR spectra pre-treatment was performed transforming the diffuse reflectance measured in absorbance (log [1/R]). Subsequently, signal interferences of a multiplicative type, those due to particle size and those associated with changes in wavelength, were eliminated with the SNV correction algorithm (Barnes et al., 1989).

The predictive models were then obtained by PLS regression (Naes et al., 2002). The optimal number of latent variables was calculated using the Venetian blinds crossvalidation procedure. Root mean squared errors of calibration (RMSEC) and crossvalidation (RMSECV) and the respective coefficients of determination were calculated to check the validity of the results. Minimum RMSECV values and number of latent variables were used as the selection criteria for the number of latent variables to be included in the model. New latent variables were included if they provided a reduction of RMSECV higher than $2 \%$.

At this point, the software provides information regarding outliers in the NIR spectra. The considerations explained by Porep et al. (2015) regarding the identification and removal of outliers were taken into account. Consequently, outliers were removed considering the values of the Hotelling $\mathrm{T}^{2}$ statistics and the $\mathrm{Q}$ residues. In the case of response variables, the values of the normalized residuals $(<-3$ or $>3)$ and leverage parameters were considered. Then, a definite PLS regression model was recalculated, and the spectra of the samples of the validation group were used to make predictions, 
calculating the coefficient of determination and root mean squared errors of prediction (RMSEP). RMSEP values were also contextualized using the mean (\%mean) of the validation group. Residual prediction deviation (RPD), representing the ratio between the standard deviation of the validation and RMSEP, was calculated to provide a better comparison between models obtained with different samples. Usually, RPD values higher than 2 represent useful models for classification or quantification (Fearn, 2002).

The reliability of the specific models was studied applying each model to the rest of sample sets. In order to analyse the reliability of general models, five new general models were calculated with four of the sample sets for the calibration and crossvalidation and they were later applied to predict the contents using the spectra of the remaining specific sample set.

The pre-treatment of the spectra, PLS regression models, detection of outliers, error parameters and goodness of fit for each model were performed with Matlab $\vee 9.4$ (Mathworks Inc, Natick, MA, USA) using the PLS_Toolbox v 8.2.1 module (Eigenvector Research Inc, Wenatchee, WA, USA).

\section{Results and discussion}

The calibration and validation groups for the specific and general model had similar means and coefficients of variation (Table 1). As expected, the set with cherry and cocktail tomatoes had the highest SSC, and contents of fructose, glucose and citric and malic acids. The group with tomato landraces also had high sugar content, but with much lower citric acid accumulation. In general, a higher level of variation was found for acid contents than for sugars.

alt-text: Table 1

Table 1

(i) The presentation of Tables and the formatting of text in the online proof do not match the final output, though the data is the same. To preview the actual presentation, view the Proof.

Statistical parameters of the sample sets used for the calibration and validation of PLS models. $\mathrm{N}_{\mathrm{C}}$ : number of samples used for calibration; $\mathrm{N}_{\mathrm{V}}$ number of samples used for validation. $\mathrm{N}$ : Navarra; $\mathrm{E}$ : Extremadura.

\begin{tabular}{|c|c|c|c|c|c|c|c|c|c|}
\hline & \multirow[b]{2}{*}{ Model $\left(\mathbf{N}_{\mathbf{c}} / \mathbf{N}_{\mathbf{v}}\right)$} & \multicolumn{4}{|c|}{ Calibration } & \multicolumn{4}{|c|}{ Validation } \\
\hline & & Mean & SD & Range & $\begin{array}{l}\text { CV } \\
(\%)\end{array}$ & Mean & SD & Range & $\begin{array}{l}\text { CV } \\
(\%)\end{array}$ \\
\hline $\mathrm{SSC}^{\circ} \mathrm{Brix}$ & $\begin{array}{l}\text { Processing } \\
\text { tomato } \mathrm{N}\end{array}$ & 4.53 & 0.56 & $3.45-6.10$ & 12.3 & 4.54 & 0.48 & $3.60-5.50$ & 10.6 \\
\hline
\end{tabular}


$(135 / 45)$

Processing

tomato $\mathrm{E}$

4.57

$\mid$

$(126 / 42)$

\begin{tabular}{|l|l|l|l|l|l|l|}
\hline 0.47 & $3.50-5.80$ & 10.3 & 4.51 & 0.41 & $3.65-5.35$ & 9.2 \\
\hline
\end{tabular}

(n)

Cherry\&cocktail

$(80 / 26)$

\begin{tabular}{|l|l|l}
\hline 5.64 & 1.08 & $3.95-9.15$
\end{tabular}

19.15 .51

$1.14 \quad 3.50-9.00$

20.6

Mid-sized tomato

$(81 / 27)$

\begin{tabular}{|l|l|l|l|l|l|l|l|}
\hline 4.30 & 0.55 & $2.95-5.65$ & 12.9 & 4.31 & 0.55 & $3.45-5.40$ & 12.7 \\
\hline
\end{tabular}

Tomato

landraces

5.42

$0.42 \quad 4.30-6.20$

\begin{tabular}{l|l}
7.7 & 5.32
\end{tabular}

$0.53 \quad 4.20-6.20$

10.0

$(66 / 22)$

General model

$(487 / 163)$

\begin{tabular}{l|l|l}
4.72 & 0.580 & $2.95-9.00$
\end{tabular}

\begin{tabular}{l|l|l|l}
16.9 & 4.79 & 0.82 & $3.45-9.15$
\end{tabular}

17.2

Processing

tomato $\mathrm{N}$

(135/45)

\begin{tabular}{|l|l|l|l|l|l|l|l|}
\hline 13.42 & 2.85 & $5.84-22.42$ & 21.2 & 12.47 & 3.12 & $7.16-19.21$ & 25.0
\end{tabular}

Processing

tomato $\mathrm{E}$

$14.46 \quad 2.89$

$8.30-20.04$

(126/42)

Cherry\&cocktail

Fructose $\mathrm{g}$
$\mathrm{kg}^{-1} \mathrm{fw}$

$(80 / 26)$

\begin{tabular}{|l|l|l|l|l|l|l|l|}
\hline 19.90 & 5.63 & $12.09-38.26$ & 28.3 & 19.67 & 5.74 & $10.35-38.30$ & 29.2 \\
\hline
\end{tabular}

Mid-sized tomato

(81/27)

13.523 .56

8.15-25.63

(2)

\begin{tabular}{|c|c|c|c|c|c|c|c|c|c|}
\hline & $\begin{array}{l}\text { Mid-sized tomato } \\
(81 / 27)\end{array}$ & 13.52 & 3.56 & $8.15-25.63$ & 26.3 & 13.86 & 3.88 & $8.84-22.75$ & 28.0 \\
\hline & $\begin{array}{l}\text { Tomato } \\
\text { landraces } \\
(66 / 22)\end{array}$ & 19.42 & 2.35 & $13.85-23.60$ & 12.1 & 19.02 & 2.71 & $13.92-22.95$ & 14.2 \\
\hline & $\begin{array}{l}\text { General model } \\
(487 / 163)\end{array}$ & 15.14 & 4.36 & 7.16-38.30 & 28.8 & 15.00 & 4.96 & 5.09-36.85 & 33.0 \\
\hline \multirow[t]{5}{*}{$\begin{array}{l}\text { Glucose g } \\
\mathrm{kg}^{-1} \mathrm{fw}\end{array}$} & $\begin{array}{l}\text { Processing } \\
\text { tomato } \mathrm{N} \\
(135 / 45)\end{array}$ & 12.15 & 2.79 & $6.10-20.87$ & 22.9 & 11.67 & 2.54 & $7.42-17.16$ & 21.8 \\
\hline & $\begin{array}{l}\text { Processing } \\
\text { tomato E } \\
(126 / 42)\end{array}$ & 14.08 & 2.51 & $7.60-19.69$ & 18.4 & 13.88 & 1.82 & 10.17-18.67 & 13.1 \\
\hline & $\begin{array}{l}\text { Cherry\&cocktail } \\
(80 / 26)\end{array}$ & 17.30 & 5.91 & $9.09-37.25$ & 34.2 & 17.50 & 6.61 & 7.71-38.63 & 37.8 \\
\hline & $\begin{array}{l}\text { Mid-sized tomato } \\
(81 / 27)\end{array}$ & 11.86 & 3.34 & $6.73-22.72$ & 28.1 & 12.24 & 3.45 & 7.11-20.14 & 28.2 \\
\hline & Tomato & 17.71 & 2.67 & $11.02-22.11$ & 15.1 & 17.26 & 3.18 & $11.13-21.86$ & 18.4 \\
\hline
\end{tabular}




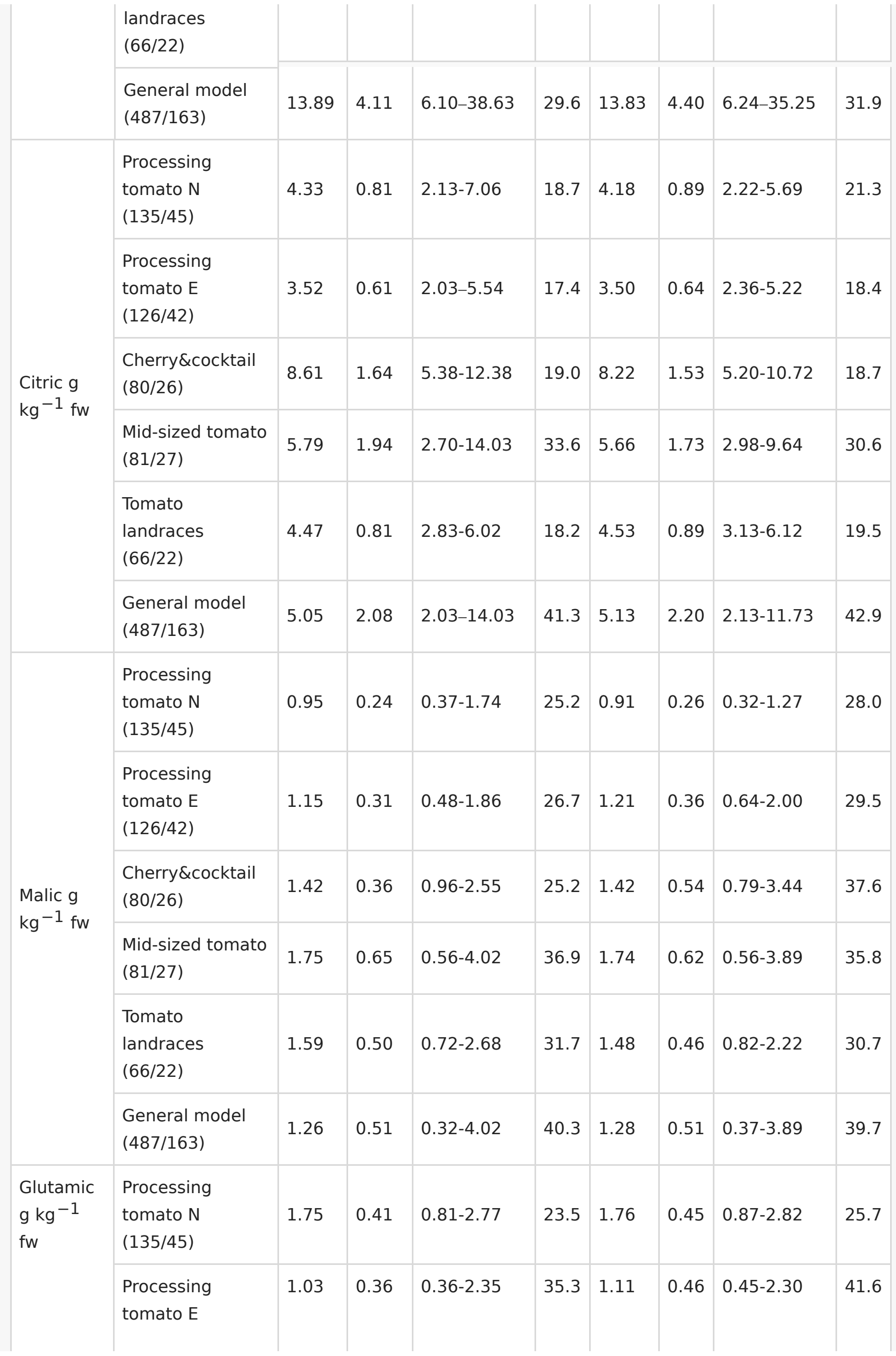




\begin{tabular}{|l|l|l|l|l|l|l|l|l|}
\hline $\begin{array}{l}\text { (126/42) } \\
\text { Cherry\&cocktail }\end{array}$ & 1.43 & 0.91 & $0.28-4.35$ & 63.7 & 1.40 & 0.97 & $0.32-4.10$ & 69.7 \\
\hline $\begin{array}{l}\text { Mid-sized tomato } \\
(81 / 27)\end{array}$ & 1.71 & 0.75 & $0.70-4.25$ & 44.0 & 1.64 & 0.69 & $0.74-3.70$ & 42.1 \\
\hline $\begin{array}{l}\text { Tomato } \\
\text { landraces } \\
(66 / 22)\end{array}$ & 1.97 & 0.44 & $0.92-2.88$ & 22.5 & 1.87 & 0.45 & $0.93-2.65$ & 23.8 \\
\hline $\begin{array}{l}\text { General model } \\
(487 / 163)\end{array}$ & 1.50 & 0.66 & $0.28-4.35$ & 43.9 & 1.50 & 0.68 & $0.43-4.22$ & 45.2 \\
\hline
\end{tabular}

\subsection{Prediction models}

\subsubsection{SSCd}

Most published works based in non-destructive methods for fruits with thin or thick rind have focused their interest in the indirect quantification of basic parameters such as SSC, titratable acidity and $\mathrm{pH}$ (Arendse et al., 2018). In the case of SSC, the performance for prediction varies in each study, with $R^{2}=0.9$ and $R M S E P=0.4$ for apple (Giovanelli et al., 2014), $R^{2}=0.88$ and RMSEP $=0.46$ for pear ( $X u$ et al., 2012), $R^{2}=0.93$ and RMSEP $=0.62$ in peach (Shao et al., 2011) and $R^{2}=0.82$ and RMSEP $=0.85$ in cherry (Escribano et al., 2017).

Tomato has also received attention. Even though only one variety has been used in most studies, the performance of NIR based predictions have not been always satisfactory. de Oliveira et al. (2014) tried to develop NIR models predicting SCC in different fruits but concluded that the methodology was not appropriate for fruits with heterogeneous internal structure such as tomato. In fact, their performance for prediction with a single variety was $\mathrm{R}^{2}=0.53$ and $\mathrm{RMSEP}=0.53$ (\%RMSEP $=8.9 \%$ ). Other authors have obtained better performances with their materials. Saad et al. (2016) reached $\mathrm{R}^{2}=0.91$ and $\mathrm{SEP}=0.28$, again with a single variety. Ecarnot et al. (2013) with the model cultivar "Microtom" obtained a performance for prediction with $\mathrm{R}^{2}=0.82$ and RMSEP $=0.45$. Torres et al. (2015) with an obsolete variety, but highly appreciated in the Spanish market, obtaining performances for the prediction with $\mathrm{R}^{2}=0.60-0.75$ and SEP $=0.83-0.65$, depending on the hardware used. These last results are similar to the previously obtained by Flores et al. (2009) with the same variety and a validation group of 100 samples $\left(R^{2}=0.77\right.$ and $\left.S E P=0.68\right)$.

In the present work, the performance was highly dependent on the tomato type considered, with $\mathrm{R}^{2} \mathrm{p}$ values for prediction ranging from 0.92 in tomato landraces to 0.51 for processing tomato grown in Navarra (Table 2). RMSEP values also ranged from 
0.14 to 0.46 , which represented $2.7 \%-8.4 \%$ of the mean value of the validation. RPD values were close to 2 , considered a limit to define useful models (Fearn, 2002). These values are similar or even improve those obtained in previous works in tomato or other crops. It is true that the range of variation present in the samples of the calibration model was greater than in other works. This was expected as most works deal with a single variety and in the present work several varieties are present in each specific model. But at the same time this fact also represented a challenge, considering that the interference of the internal structure of tomatoes (pericarp width, number and size of locules, juiciness ...) would be much higher as it was much more varied, and differences in internal structure hinder the development of efficient models (de Oliveira et al., 2014 ).

\section{alt-text: Table 2}

Table 2

(i) The presentation of Tables and the formatting of text in the online proof do not match the final output, though the data is the same. To preview the actual presentation, view the Proof.

Performance of NIR based models using partial least squares (PLS) regression predicting contents of tast related compounds. SSC: soluble solids content; $\mathrm{R}^{2}$ coefficient of determination; RMSE: root mean squar error; NC: number of samples in the calibration group. NV: number of samples in the validation group; C: calibration; CV: cross-validation; P: prediction; RPD: residual prediction deviation. The number of outliers includes the sum of cases from both the calibration and validation group.

\begin{tabular}{|c|c|c|c|c|c|c|c|c|c|}
\hline & $\operatorname{Model}\left(\mathbf{N}_{\mathrm{C}} / \mathbf{N}_{\mathbf{v}}\right)$ & Outliers & $R^{2} C$ & RMSEC & $\mathrm{R}^{2} \mathrm{CV}$ & RMSECV & $R^{2} P$ & RMSEP & $\begin{array}{l}\text { \%RMSEP } \\
\text { (Mean) }\end{array}$ \\
\hline \multirow{6}{*}{$\mathrm{SSC}^{\circ}$ Brix } & $\begin{array}{l}\text { Processing } \\
\text { tomato } \mathrm{N} \\
(135 / 45)\end{array}$ & 7 & 0.89 & 0.18 & 0.06 & 0.69 & 0.72 & 0.23 & 5.1 \\
\hline & $\begin{array}{l}\text { Processing } \\
\text { tomato E } \\
(126 / 42)\end{array}$ & 13 & 0.81 & 0.20 & 0.25 & 0.43 & 0.51 & 0.28 & 6.2 \\
\hline & $\begin{array}{l}\text { Cherry\&cocktail } \\
(80 / 26)\end{array}$ & 4 & 0.92 & 0.31 & 0.52 & 0.78 & 0.87 & 0.46 & 8.4 \\
\hline & $\begin{array}{l}\text { Mid-sized } \\
\text { tomato }(81 / 27)\end{array}$ & 10 & 0.88 & 0.18 & 0.64 & 0.32 & 0.63 & 0.34 & 7.9 \\
\hline & $\begin{array}{l}\text { Tomato } \\
\text { landraces } \\
(66 / 22)\end{array}$ & 4 & 0.97 & 0.07 & 0.33 & 0.36 & 0.92 & 0.14 & 2.7 \\
\hline & $\begin{array}{l}\text { General model } \\
(487 / 163)\end{array}$ & 8 & 0.73 & 0.41 & 0.47 & 0.61 & 0.62 & 0.47 & 9.8 \\
\hline
\end{tabular}




\begin{tabular}{|c|c|c|c|c|c|c|c|c|c|}
\hline \multirow[t]{6}{*}{$\begin{array}{l}\text { Fructose } \\
\mathrm{g} \mathrm{kg}^{-1} \\
\mathrm{fw}\end{array}$} & $\begin{array}{l}\text { Processing } \\
\text { tomato } \mathrm{N} \\
(135 / 45)\end{array}$ & 8 & 0.73 & 1.35 & 0.08 & 2.91 & 0.49 & 1.95 & 15.6 \\
\hline & $\begin{array}{l}\text { Processing } \\
\text { tomato E } \\
(126 / 42)\end{array}$ & 8 & 0.78 & 1.35 & 0.35 & 2.44 & 0.58 & 1.69 & 11.7 \\
\hline & $\begin{array}{l}\text { Cherry\&cocktail } \\
(80 / 26)\end{array}$ & 8 & 0.86 & 2.07 & 0.52 & 4.04 & 0.81 & 2.32 & 11.8 \\
\hline & $\begin{array}{l}\text { Mid-sized } \\
\text { tomato }(81 / 27)\end{array}$ & 9 & 0.82 & 1.47 & 0.29 & 3.05 & 0.32 & 2.94 & 21.2 \\
\hline & $\begin{array}{l}\text { Tomato } \\
\text { landraces } \\
(66 / 22)\end{array}$ & 7 & 0.93 & 0.64 & 0.19 & 2.29 & 0.82 & 1.15 & 6.0 \\
\hline & $\begin{array}{l}\text { General model } \\
(487 / 163)\end{array}$ & 14 & 0.58 & 2.76 & 0.41 & 3.31 & 0.47 & 3.24 & 21.6 \\
\hline \multirow{6}{*}{$\begin{array}{l}\text { Glucose } \\
\mathrm{g} \mathrm{kg}^{-1} \\
\mathrm{fw}\end{array}$} & $\begin{array}{l}\text { Processing } \\
\text { tomato } \mathrm{N} \\
(135 / 45)\end{array}$ & 16 & 0.78 & 1.12 & 0.18 & 2.39 & 0.42 & 1.51 & 13.0 \\
\hline & $\begin{array}{l}\text { Processing } \\
\text { tomato E } \\
(126 / 42)\end{array}$ & 9 & 0.75 & 1.21 & 0.25 & 2.23 & 0.50 & 1.66 & 12.0 \\
\hline & $\begin{array}{l}\text { Cherry\&cocktail } \\
(80 / 26)\end{array}$ & 6 & 0.80 & 2.47 & 0.58 & 3.66 & 0.62 & 2.87 & 16.4 \\
\hline & $\begin{array}{l}\text { Mid-sized } \\
\text { tomato }(81 / 27)\end{array}$ & 14 & 0.84 & 1.30 & 0.28 & 2.94 & 0.38 & 2.49 & 20.4 \\
\hline & $\begin{array}{l}\text { Tomato } \\
\text { landraces } \\
(66 / 22)\end{array}$ & 6 & 0.91 & 0.80 & 0.22 & 2.54 & 0.73 & 1.49 & 8.7 \\
\hline & $\begin{array}{l}\text { General model } \\
(487 / 163)\end{array}$ & 14 & 0.57 & 2.54 & 0.41 & 2.98 & 0.46 & 2.92 & 21.1 \\
\hline \multirow[t]{4}{*}{$\begin{array}{l}\text { Citric g } \\
\mathrm{kg}^{-1} \mathrm{fw}\end{array}$} & $\begin{array}{l}\text { Processing } \\
\text { tomato } \mathrm{N} \\
(135 / 45)\end{array}$ & 15 & 0.81 & 0.28 & 0.04 & 0.80 & 0.71 & 0.43 & 10.2 \\
\hline & $\begin{array}{l}\text { Processing } \\
\text { tomato E } \\
(126 / 42)\end{array}$ & 18 & 0.79 & 0.25 & 0.06 & 0.62 & 0.65 & 0.31 & 8.8 \\
\hline & $\begin{array}{l}\text { Cherry\&cocktail } \\
(80 / 26)\end{array}$ & 5 & 0.53 & 1.11 & 0.22 & 1.50 & 0.46 & 1.17 & 14.2 \\
\hline & Mid-sized & 8 & 0.68 & 0.96 & 0.30 & 1.47 & 0.40 & 1.33 & 23.5 \\
\hline
\end{tabular}




\begin{tabular}{|c|c|c|c|c|c|c|c|c|c|}
\hline & tomato $(81 / 27)$ & & & & & & & & \\
\hline & $\begin{array}{l}\text { Tomato } \\
\text { landraces } \\
(66 / 22)\end{array}$ & 5 & 0.94 & 0.19 & 0.54 & 0.57 & 0.88 & 0.31 & 6.9 \\
\hline & $\begin{array}{l}\text { General model } \\
(487 / 163)\end{array}$ & 23 & 0.84 & 0.80 & 0.73 & 1.01 & 0.75 & 1.00 & 19.5 \\
\hline \multirow{6}{*}{$\begin{array}{l}\text { Malic g } \\
\mathrm{kg}^{-1} \mathrm{fw}\end{array}$} & $\begin{array}{l}\text { Processing } \\
\text { tomato } \mathrm{N} \\
(135 / 45)\end{array}$ & 4 & 0.79 & 0.11 & 0.30 & 0.21 & 0.71 & 0.15 & 16.6 \\
\hline & $\begin{array}{l}\text { Processing } \\
\text { tomato E } \\
(126 / 42)\end{array}$ & 9 & 0.83 & 0.12 & 0.52 & 0.21 & 0.73 & 0.16 & 13.0 \\
\hline & $\begin{array}{l}\text { Cherry\&cocktail } \\
(80 / 26)\end{array}$ & 7 & 0.81 & 0.16 & 0.48 & 0.27 & 0.72 & 0.18 & 12.6 \\
\hline & $\begin{array}{l}\text { Mid-sized } \\
\text { tomato }(81 / 27)\end{array}$ & 10 & 0.80 & 0.23 & 0.50 & 0.37 & 0.62 & 0.29 & 16.6 \\
\hline & $\begin{array}{l}\text { Tomato } \\
\text { landraces } \\
(66 / 22)\end{array}$ & 5 & 0.96 & 0.10 & 0.48 & 0.37 & 0.90 & 0.15 & 10.3 \\
\hline & $\begin{array}{l}\text { General model } \\
(487 / 163)\end{array}$ & 23 & 0.69 & 0.27 & 0.53 & 0.35 & 0.67 & 0.28 & 21.9 \\
\hline \multirow{6}{*}{$\begin{array}{l}\text { Glutamic } \\
\mathrm{g} \mathrm{kg}^{-1} \\
\mathrm{fw}\end{array}$} & $\begin{array}{l}\text { Processing } \\
\text { tomato N } \\
(135 / 45)\end{array}$ & 12 & 0.75 & 0.20 & 0.17 & 0.39 & 0.35 & 0.25 & 14.2 \\
\hline & $\begin{array}{l}\text { Processing } \\
\text { tomato E } \\
(126 / 42)\end{array}$ & 14 & 0.75 & 0.18 & 0.35 & 0.30 & 0.54 & 0.24 & 21.3 \\
\hline & $\begin{array}{l}\text { Cherry\&cocktail } \\
(80 / 26)\end{array}$ & 4 & 0.85 & 0.35 & 0.62 & 0.57 & 0.74 & 0.48 & 34.3 \\
\hline & $\begin{array}{l}\text { Mid-sized } \\
\text { tomato }(81 / 27)\end{array}$ & 14 & 0.73 & 0.32 & 0.23 & 0.59 & 0.26 & 0.51 & 31.2 \\
\hline & $\begin{array}{l}\text { Tomato } \\
\text { landraces } \\
(66 / 22)\end{array}$ & 8 & 0.94 & 0.10 & 0.39 & 0.34 & 0.81 & 0.16 & 8.7 \\
\hline & $\begin{array}{l}\text { General model } \\
(487 / 163)\end{array}$ & 30 & 0.51 & 0.43 & 0.31 & 0.53 & 0.36 & 0.50 & 33.1 \\
\hline
\end{tabular}


The general model including all the samples had a performance similar to the worse specific model, with $\mathrm{R}^{2} \mathrm{P}=0.62$ and $\mathrm{RMSEP}=0.47^{\circ} \mathrm{Brix}$, which represents $9.8 \%$ of the mean contents (Table 2). Despite being higher, the values obtained with the general model are still similar to those described by other works with a limited range of varietal variation, and would still be interesting in order to minimize costs in wide screening programs.

The robustness of the models was tested trying to apply each of the specific models obtained to the samples of the rest of sample sets. On the other hand, new general models were calculated with the data of four of the five sample sets and then they were applied to predict the contents of the remaining one. None of the specific models passed the test (Table 3 ). The highest $R^{2}{ }_{P}$ values for the predictions with external assays was 0.20 , and RMSEP values ranged from 0.5 to 5.10 in absolute values, and from $10.6 \%$ to $100.2 \%$ in values contextualized with the mean.

alt-text: Table 3

Table 3

(i) The presentation of Tables and the formatting of text in the online proof do not match the final output, though the data is the same. To preview the actual presentation, view the Proof.

Performance of NIR based models using partial least squares (PLS) regression for cross-predicting soluble solids content in other assays. SSC: soluble solids content; $\mathrm{R}^{2} \mathrm{P}$ coefficient of determination of the predictions; RMSEP: root mean squared error of the predictions. N: Navarra; E: Extremadura. For each sample set (calibration and validation), the number of samples is indicated.

\begin{tabular}{|c|c|c|c|c|}
\hline Model calibration & Model validation & $R^{2} P$ & RMSEP ${ }^{\circ}$ Brix & $\begin{array}{l}\text { \%RMSEP } \\
\text { (Mean) }\end{array}$ \\
\hline \multirow{5}{*}{$\begin{array}{l}\text { Processing tomato }(\mathrm{N})(168 \\
\text { samples) }\end{array}$} & $\begin{array}{l}\text { Processing tomato }(E) \text { (180 } \\
\text { samples) }\end{array}$ & 0.031 & 0.65 & 14.4 \\
\hline & Cherry\&cocktail (106 samples) & 0.026 & 5.10 & 90.9 \\
\hline & $\begin{array}{l}\text { Mid-sized tomato (108 } \\
\text { samples) }\end{array}$ & 0.002 & 4.28 & 100.2 \\
\hline & $\begin{array}{l}\text { Tomato landraces (88 } \\
\text { samples) }\end{array}$ & 0.126 & 0.74 & 13.7 \\
\hline & General (482 samples) & 0.002 & 3.49 & 72.7 \\
\hline \multirow[t]{3}{*}{$\begin{array}{l}\text { Processing tomato }(\mathrm{E})(180 \\
\text { samples) }\end{array}$} & $\begin{array}{l}\text { Processing tomato }(\mathrm{N}) \text { (168 } \\
\text { samples) }\end{array}$ & 0.001 & 0.71 & 15.4 \\
\hline & Cherry\&cocktail (106 samples) & 0.000 & 2.65 & 47.2 \\
\hline & Mid-sized tomato (108 & 0.003 & 2.19 & 51.3 \\
\hline
\end{tabular}




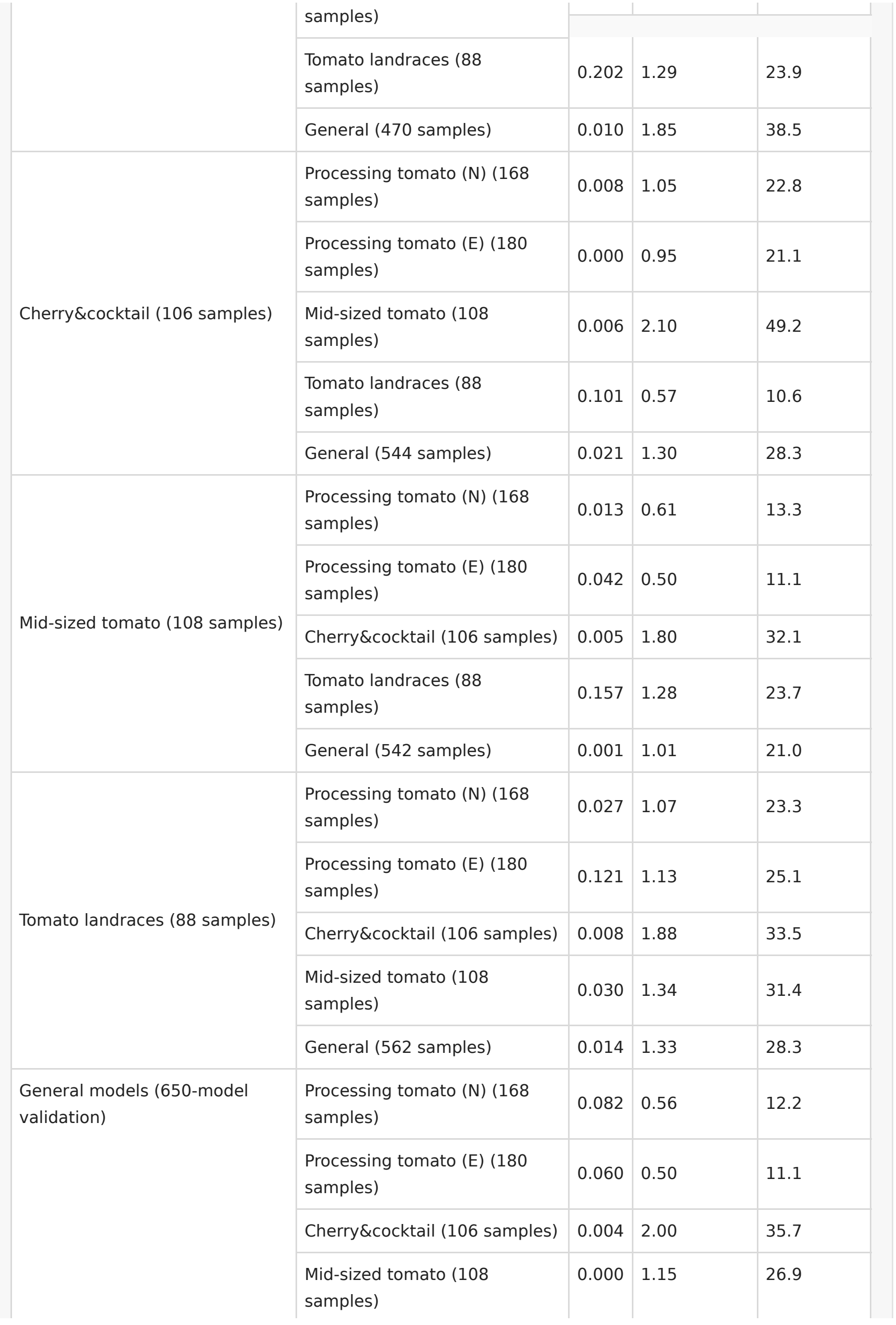


Among the different models applied to predict the rest of assays, the one corresponding to mid-sized tomatoes and the general models had the lowest mean \%RMSEP values ( $20.2 \%$ and $20.6 \%$ respectively) with absolute values close to $1^{\circ}$ Brix (Table 3 ). In the case of the new general models, $\mathrm{R}^{2}{ }_{\mathrm{P}}$ values were close to 0 , with mean \%RMSEP values ranging from $11.1 \%$, when it was applied to predict the contents of processing tomato grown in Extremadura to 35.7\%, when applied to make predictions with cherry and cocktail tomato, and averaging $20.6 \%$ (Table 3 ).

On the other hand, when the different models were applied to predict the contents of the samples of processing tomato grown either in Navarra or Extremadura and tomato landraces, a lower mean \%RMSEP was obtained (17.4, 16.6 and $17.8 \%$ respectively). The samples from the cherry and cocktail set and mid-sized tomatoes were more difficult to predict using external calibrations.

It is difficult to compare these results with other works, as it is unusual to find the application of the obtained models to external assays. Escribano et al. (2017), in their work with two cherry varieties tried to apply the models of one of the varieties to the other. In that case, the authors concluded that models for SSC did not need to be specific to the variety to be measured to perform adequately. In the present work, neither specific models nor general models were robust enough as to offer reliable predictions in other assays. Even those developed the same varieties and growing conditions but applied to predict contents of samples obtained in a different environment failed to offer a reliable performance. This result emphasizes the need to develop specific calibrations for each assay in order to minimize the error in the indirect predictions.

\subsubsection{Sugars and acids}

The performance of specific PLS models for the prediction of fructose and glucose was highly dependent on the varietal type considered. Mean \%RMSEP values of $13.3 \%$ and 14.1 were obtained for fructose and glucose respectively, with $R^{2}$ p values for prediction ranging from 0.32 to 0.82 (Table 2). Nonetheless, the model for mid-sized tomato offered comparatively high errors, up to $21.2 \%$ for fructose and $20.4 \%$ for glucose. This group was formed by highly heterogeneous varieties, including flat salad type tomato, plum tomato and cluster tomatoes. The rather heterogeneous internal structure of the varieties would be probably originating a higher level of error in the predictions.

The performance of the general model was highly influenced by the worse specific model, with $\mathrm{R}^{2}$ for prediction of 0.47 for fructose and 0.46 for glucose and \%RMSEP 
values of $21.6 \%$ and $21.1 \%$. As in the case of SSC, general models proved to have low efficacy. Consequently, in this case it would also be recommended to rely on specific models.

Few articles on the determination of specific sugars are available for the quantification of specific compounds, as most published works rely on the determination of basic parameters such as SSC and titratable acidity (Arendse et al., 2018). Among the different limitations of non-destructive NIR spectroscopy for this purpose, the scattering typical of non-transparent media and assignment of NIR bands to specific compounds which absorb in the MIR region have been suggested (Porep et al., 2015). Nonetheless, some data is available. For example, Torres et al. (2015), with a single variety obtained SEP values of 3.8 and 4.0 for fructose and 4.2 for glucose and $R^{2}$ values ranging from 0.35 to 0.52 , depending on the hardware. Considering mean contents in that work, those values would represent contextualized errors of $20.1 \%-21.2 \%$ for fructose and $19.3 \%$ for glucose. Better results were reported by Pedro and Ferreira (2007) with \%SEP values of $13.4 \%$ for fructose and $11.6 \%$ for glucose. In that case, the authors also used diffuse reflectance, but they analyzed samples of tomato concentrate, involving homogenized samples with higher sugar contents. Therefore, a better performance would be logically expected.

The performance of specific models for the indirect quantification of acids was similar to those obtained for sugars, though a worse performance was obtained for glutamic acid. Mean \%RMSEP values of $12.7 \%, 13.8 \%$ and $21.9 \%$ were obtained for citric, malic and glutamic acid respectively (Table 2). Again, the models for mid-sized tomatoes tended to show a worse performance and the efficiency of the general model was lower than that of the worse specific model. Torres et al. (2015) also modelled citric and malic acid accumulation in their work, obtaining SEP values of $0.81-0.86$ and 0.22 respectively, which would represent $18.1-19.2 \%$ and $16.5 \%$ of the reported mean contents respectively. Most specific models improved these results, while the model for mid-sized tomatoes had similar error levels.

In perspective, mean \%RMSEP values obtained in the present work are lower than $15 \%$ for fructose, glucose, citric and malic acids, using specific models based on different varieties. These values are considerably good, bearing in mind that they are obtained directly on intact fruits with heterogeneous internal structure. It is true though that the higher level of heterogeneity in fruit internal structure will result in inferior performance, as reported by de Oliveira et al. (2014). That would mean that in order to develop useful models in the industry, the calibration and prediction groups should be formed by fruits with similar structures.

Models based on FT-MIR can be more accurate than those obtained with NIR (Schulz and Baranska, 2009). But the high absorption of MIR radiation in biological tissues entails a 
low penetration depth, allowing only superficial measurements of a few micrometers ( Porep et al., 2015). That means, that MIR indirect measurements require a previous homogenization of the sample and centrifugation of the juices obtained. Undoubtedly, this prior homogenization contributes to a higher accuracy.

The selection of the most appropriate methodology will remain a decision for each industrial/agronomical application. It will be necessary to choose between highthroughput indirect analysis directly on intact fruits with NIR models, with higher error levels and the need to obtained specific calibrations, or obtaining more accurate indirect measurements with general models, but involving a cumbersome preprocessing of samples.

\section{Conclusions}

One of the main limitations of non-destructive indirect predictions of taste-related compounds based on NIR spectra is that different internal structures of tomatoes can critically affect the performance of the models. In fact, most of the published work available relies on a single tomato variety. Our work proves that it is possible to obtain models with good performance despite this limitation. These models can include several varieties within a specific varietal type and will represent a valuable tool to quantify gross measurements such as soluble solid contents, or even the individual accumulation of fructose, glucose and citric and malic acids. General models can also be obtained, representing a higher number of samples and variability, but their performance would not be better than specific models. More importantly, models must be calibrated for each assay, as the performance of specific or general models to samples obtained in new assays is unacceptable.

\section{Conflicts of interest}

The authors declare no conflict of interest.

\section{Ackowledgements}

This research was performed despite the lack of direct public funding for its development and thanks to the enthusiasm of the authors. The authors thank Dr. Lahoz and Dr. Campillo for providing processing tomato samples and Dr. Moreno for providing samples from tomato landraces. G. Ibañez thanks Universitat Jaume I for funding his pre-doctoral grant (PREDOC/2015/45).

\section{References}

(i) The corrections made in this section will be reviewed and approved by journal production editor. 
Arendse, E., Fawole, O.A., Magwaza, L.S., Opara, U.L., 2018. Non-destructive prediction of internal and external quality attributes of fruit with thick rind: a review. J. Food Eng. 217, 11-23. Available from: https://doi.org/10.1016/j.jfoodeng. 2017.08.009.

Baldwin, E.A., Scott, J.W., Einstein, M.A., Malundo, T.M.M., Carr, B.T., Shewfelt, R.L., Tandon, K.S., 1998. Relationship between sensory and instrumental analysis for tomato flavor. J. Am. Soc. Hortic. Sci. 123 (5), 906-915. Available from: https://doi.o $\mathrm{rg} / 10.21273 / \mathrm{JASHS} .123 .5 .906$.

Baldwin, E.A., Scott, J.W., Shewmaker, C.K., Schuch, W., 2000. Flavor trivia and tomato aroma: biochemistry and possible mechanisms for control of important aroma components. Hortscience 35 (6), 1013-1021. Available from: https://doi.org/ 10.21273/HORTSCI.35.6.1013.

Baldwin, E.A., Goodner, K., Plotto, A., 2008. Interaction of volatiles, sugars, and acids on perception of tomato aroma and flavor descriptors. J. Food Sci. 73 (6), S294-S307. Available from: https://doi.org/10.1111/j.1750-3841.2008.00825.x.

Barnes, R.J., Dhanoa, M.S., Lister, S.J., 1989. Standard normal variate transformation and de-trending of near-infrared diffuse reflectance spectra. Appl. Spectrosc. 43 (5), 772-777. Available from: https://doi.org/10.1366/000370289420 $\underline{2201}$.

Bazzani, C., Canavari, M., 2013. Forecasting a scenario of the fresh tomato market in Italy and in Germany using the Delphi method. Br. Food J. 115 (3), 448-459. Available from: https://doi.org/10.1108/00070701311314246.

Blanco, M., Villarroya, I., 2002. NIR spectroscopy: a rapid-response analytical tool. Trac. Trends Anal. Chem. 21 (4), 240-250. Available from: https://doi.org/10.1016/S 0165-9936(02)00404-1.

Bucheli, P., Voirol, E., de la Torre, R., López, J., Rytz, A., Tanksley, S.D., Pétiard, V., 1999. Definition of nonvolatile markers for flavor of tomato (Lycopersicon esculentum Mill.) as tools in selection and breeding. J. Agric. Food Chem. 47 (2), 659-664. Available from: https://doi.org/10.1021/jf980875I.

Bureau, S., Cozzolino, D., Clark, C.J., 2019. Contributions of Fourier-transform mid infrared (FT-MIR) spectroscopy to the study of fruit and vegetables: a review. Postharvest Biol. Technol. 148, 1-14. Available from: https://doi.org/10.1016/j.posth arvbio.2018.10.003. 
Cebolla-Cornejo, J., Valcárcel, M., Herrero-Martínez, J.M., Roselló, S., Nuez, F., 2012. High efficiency joint CZE determination of sugars and acids in vegetables and fruits. Electrophoresis 33 (15), 2416-2423. Available from: https://doi.org/10.1002/ elps.201100640.

de Oliveira, G.A., Bureau, S., Renard, C.M.G.C., Pereira-Netto, A.B., de Castilhos, F., 2014. Comparison of NIRS approach for prediction of internal quality traits in three fruit species. Food Chem. 143, 223-230. Available from: https://doi.org/10.1016/j.fo odchem.2013.07.122.

Ecarnot, M., Bączyk, P., Tessarotto, L., Chervin, C., 2013. Rapid phenotyping of the tomato fruit model, Micro-Tom, with a portable VIS-NIR spectrometer. Plant Physiol. Biochem. 70, 159-163. Available from: https://doi.org/10.1016/j.plaphy.2013.05.01 9.

Escribano, S., Biasi, W.V., Lerud, R., Slaughter, D.C., Mitcham, E.J., 2017. Nondestructive prediction of soluble solids and dry matter content using NIR spectroscopy and its relationship with sensory quality in sweet cherries. Postharvest Biol. Technol. 128, 112-120. Available from: https://doi.org/10.1016/j.p ostharvbio.2017.01.016.

Fearn, T., 2002. Assessing calibrations: SEP, RPD, RER and R². NIR News 13 (6), 1213. Available from: https://doi.org/10.1255/nirn.689.

Flores, K., Sánchez, M.T., Pérez-Marín, D., Guerrero, J.E., Garrido-Varo, A., 2009. Feasibility in NIRS instruments for predicting internal quality in intact tomato. J. Food Eng. 91 (2), 311-318. Available from: https://doi.org/10.1016/j.jfoodeng.2008. $\underline{09.013}$.

Giovanelli, G., Sinelli, N., Beghi, R., Guidetti, R., Casiraghi, E., 2014. NIR spectroscopy for the optimization of postharvest apple management. Postharvest Biol. Technol. 87, 13-20. Available from: https://doi.org/10.1016/j.postharvbio.2013. $\underline{07.041 .}$.

Hahn, F., 2002. AE-automation and emerging Technologies: multi-spectral prediction of unripe tomatoes. Biosyst. Eng. 81 (2), 147-155. Available from: http s://doi.org/10.1006/bioe.2001.0035.

Lahoz, I., Leiva-Brondo, M., Martí, R., Macua, J.I., Campillo, C., Roselló, S., CebollaCornejo, J., 2016. Influence of high lycopene varieties and organic farming on the production and quality of processing tomato. Sci. Hortic. 204, 128-137. Available from: https://doi.org/10.1016/j.scienta.2016.03.042. 
Malundo, T.M.M., Shewfelt, R.L., Scott, J.W., 1995. Flavor quality of fresh tomato (Lycopersicon esculentum Mill.) as affected by sugar and acid levels. Postharvest Biol. Technol. 6 (1-2), 103-110. Available from: https://doi.org/10.1016/0925-5214 (94)00052-T.

Martí, R., Valcárcel, M., Leiva-Brondo, M., Lahoz, I., Campillo, C., Roselló, S., Cebolla-Cornejo, J., 2018. Influence of controlled deficit irrigation on tomato functional value. Food Chem. 252, 250-257. Available from: https://doi.org/10.101 6/j.foodchem.2018.01.098.

Naes, T., Isaksson, T., Fearn, T., Davies, T., 2002. A User-Friendly Guide to Multivariate Calibration and Classification, NIR Publications, Chichester, UK.

Pedro, A.M., Ferreira, M.M., 2007. Simultaneously calibrating solids, sugars and acidity of tomato products using PLS2 and NIR spectroscopy. Anal. Chim. Acta 595 (1-2), 221-227. Available from: https://doi.org/10.1016/j.aca.2007.03.036.

Porep, J.U., Kammerer, D.R., Carle, R., 2015. On-line application of near infrared (NIR) spectroscopy in food production. Trends Food Sci. Technol. 46 (2), 211-230. Available from: https://doi.org/10.1016/j.tifs.2015.10.002.

Saad, A., Jha, S.N., Jaiswal, P., Srivastava, N., Helyes, L., 2016. Non-destructive quality monitoring of stored tomatoes using VIS-NIR spectroscopy. Eng. Agric., Environ. Food 9 (2), 158-164. Available from: https://doi.org/10.1016/j.eaef.2015.1 $\underline{0.004}$.

Schulz, H., Baranska, M., 2009. Fruits and vegetables. In: Sun, D.W. (Ed.), Infrared Spectroscopy for Food Quality Analysis and Control, Elsevier Inc, New York, pp. 321-353.

Shao, Y., Bao, Y., He, Y., 2011. Visible/near-infrared spectra for linear and nonlinear calibrations: a case to predict soluble solids contents and $\mathrm{pH}$ value in peach. Food Bioprocess Technol. 4 (8), 1376-1383. Available from: https://doi.org/10.1007/s119 47-009-0227-6.

Sidhoum, A., Serra, T., 2016. Volatility spillovers in the Spanish food marketing chain: the case of tomato. Agribusiness 32 (1), 45-63. Available from: https://doi.or g/10.1002/agr.21418.

Tandon, K.S., Baldwin, E.A., Scott, J.W., Shewfelt, R.L., 2003. Linking sensory descriptors to volatile and nonvolatile components of fresh tomato flavor. J. Food Sci. 68 (7), 2366-2371. Available from: https://doi.org/10.1111/j.1365-2621.2003.tb 05774.x. 
Tieman, D., Zhu, G., Resende, M.F., Lin, T., Nguyen, C., Bies, D., et al., 2017. A chemical genetic roadmap to improved tomato flavor. Science 355 (6323), 391394. Available from: https://doi.org/10.1126/science.aal1556.

Torres, I., Pérez-Marín, D., De la Haba, M.J., Sánchez, M.T., 2015. Fast and accurate quality assessment of Raf tomatoes using NIRS technology. Postharvest Biol. Technol. 107, 9-15. Available from: https://doi.org/10.1016/j.postharvbio.2015.04.0 $\underline{04}$.

Xu, H., Qi, B., Sun, T., Fu, X., Ying, Y., 2012. Variable selection in visible and nearinfrared spectra: application to on-line determination of sugar content in pears. J. Food Eng. 109 (1), 142-147. Available from: https://doi.org/10.1016/j.jfoodeng.201 1.09.022.

\section{Highlights}

- NIR predictions for taste-related variables were obtained for different samples sets.

- The performance of the models was dependent on varietal type.

- The performance of general models did not improve those of specific models.

- NIR models could not be extrapolated to new assays.

- Internal calibration is required to provide reliable performance of predictions.

\section{Queries and Answers}

Query: Your article is registered as a regular item and is being processed for inclusion in a regular issue of the journal. If this is NOT correct and your article belongs to a Special Issue/Collection please contact b.sims@elsevier.com immediately prior to returning your corrections.

Answer: Yes

Query: Please confirm that the provided emails “ibanezg@uji.es, jaicecor@btc.upv.es, raumarre@upvnet.upv.es, mervalge@upvnet.upv.es, rosello@uji.es" are the correct address 
for official communication, else provide an alternate e-mail address to replace the existing one, because private e-mail addresses should not be used in articles as the address for communication.

Answer: All the emails are official and correct

Query: Please confirm that given names and surnames have been identified correctly and are presented in the desired order and please carefully verify the spelling of all authors' names.

Answer: Yes

Query: Please note that author's telephone/fax numbers are not published in Journal articles due to the fact that articles are available online and in print for many years, whereas telephone/fax numbers are changeable and therefore not reliable in the long term.

Answer: OK. No problem.

Query: The citation "Saad et al. (2015)" has been changed to match the author name in the reference list. Please check here and in subsequent occurrences, and correct if necessary. Answer: Ok. We agree with the change. The correct year of publicaciton is 2016.

Query: Have we correctly interpreted the following funding source(s) you cited in your article: Universitat Jaume I, Spain?

Answer: Yes 